\title{
Response of leaf-associated bacterial communities to primary acyl-homoserine lactone in the tobacco phyllosphere
}

\author{
Di Lv ${ }^{\text {a,1 }}$, Anzhou Ma ${ }^{\mathrm{a}, 1}$, Zhihui Bai ${ }^{\mathrm{a}}$, Xuliang Zhuang ${ }^{\mathrm{b}}$, Guoqiang Zhuang ${ }^{\mathrm{a} *}$ \\ ${ }^{a}$ Research Center for Eco-Environmental Sciences, Chinese Academy of Sciences, Beijing 100085, China \\ ${ }^{\mathrm{b}}$ Bureau of Science and Technology for Resources and Environment, Chinese Academy of Sciences, Beijing 100864, China
}

Received 8 July 2011; accepted 3 November 2011

Available online 22 November 2011

\begin{abstract}
The phyllosphere is inhabited by large populations of epiphytic bacteria that are able to modulate their phenotypes and behavior by quorum sensing (QS). However, the impact of acyl-homoserine lactones (AHLs) involved in QS on the ecology of bacteria in their natural habitat remains unclear. Therefore, we used a bioassay and liquid chromatography-mass spectrometry to detect AHLs in the tobacco phyllosphere. Our results identified several AHLs in the tobacco phyllosphere, the majority of which were short-chain AHLs. Furthermore, the addition of an exogenous $N$-(3-oxohexanoyl) homoserine lactone (3OC6HSL), which is seen in the naturally occurring tobacco phyllosphere, generated variability in the composition of the bacterial community as determined by denaturing gradient gel electrophoresis (DGGE) analysis and phospholipid fatty acid (PLFA) analysis. Notably, the ratio of Gram-positive (GP) bacteria increased in response to treatment with $1 \mu \mathrm{M}$ AHL, but decreased incipiently when treated with $10 \mu \mathrm{M}$ AHL. These observations provide insight into the composition of the leaf-colonizing epiphyte community responsible for AHLs, particularly GP bacteria as they do not use AHLs as signaling molecules for QS.

(C) 2011 Institut Pasteur. Published by Elsevier Masson SAS. All rights reserved.
\end{abstract}

Keywords: Phyllosphere; Acyl-homoserine lactone; Bacterial community; Epiphytes; Interaction

\section{Introduction}

Quorum sensing (QS) is a form of microbial chemical communication that relies on a cell density-dependent mechanism to modulate gene expression and alter bacterial behavior (Ng and Bassler, 2009; Waters and Bassler, 2005). By using a range of small, diffusible signal molecules, QS bacteria regulate a multitude of functions, including the production of virulence factors, bacterial motility, and symbiosis (Pacheco and Sperandio, 2009). N-acyl-homoserine lactones (AHLs) are a highly conserved class of QS signaling molecules used by a wide range of Gram-negative (GN) proteobacteria that inhabit diverse environments (Manefield and Whiteley, 2007).

\footnotetext{
* Corresponding author. Tel.: +86 106284 9613; fax: +86 1062923563.

E-mail addresses: lariena@126.com (D. Lv), azma@rcees.ac.cn (A. Ma), zhbai@rcees.ac.cn (Z. Bai), xlzhuang@rcees.ac.cn (X. Zhuang), gqzhuang@ rcees.ac.cn (G. Zhuang).

${ }^{1}$ Contributed equally to this paper.
}

Importantly, plants that have been genetically modified to synthesize AHLs have the potential to affect bacterial processes regulated by QS signals (Fray et al., 1999). While much has been learned about QS using pure bacterial cultures, little is known about environmental AHLs and their ecological roles.

The phyllosphere, with a terrestrial leaf surface area estimated to exceed $10^{8} \mathrm{~km}^{2}$ globally, is considered an important habitat for microorganisms. Bacteria are the most common colonizers of this habitat and exist in populations of approximately $10^{6}-10^{7}$ cells $/ \mathrm{cm}^{2}$ per leaf (Dulla et al., 2005). The overall microbiota in the phyllosphere is incredibly large and it should not be ignored. Phyllosphere microbial populations can also positively or negatively influence plant health and growth. Previous studies have focused mainly on bacterial plant pathogens that exhibit QS-dependent behavior, such as Pseudomonas syringae and Erwinia carotovora (Loh et al., 2002). Less is known about non-pathogenic microorganisms that inhabit the phyllosphere (Delmotte et al., 2009), 
particularly their AHL-producing counterparts. Recently, Dulla and Lindow (2009) showed that at least $7 \%$ of the culturable bacterial epiphytes from leaves can synthesize AHLs, and suggested that widespread AHL-mediated crosstalk exists in the phyllosphere. However, current knowledge of naturally occurring AHLs in the phyllosphere and their impact on leaf-associated bacterial communities is scare.

The objective of our study was to assess both the presence of AHLs and AHL-mediated influence on the composition of the leaf-associated bacterial community in the tobacco phyllosphere. The composition of the bacterial community was analyzed using cultivation-independent analysis based on phospholipid fatty acid (PLFA) and denaturing gradient gel electrophoresis (DGGE) profiles. To gain insight into the changes that were identified, sequences that corresponded to the DGGE bands were also analyzed.

\section{Materials and methods}

\subsection{Plant material and profiling of AHLs in the phyllosphere}

The tobacco plant (Nicotiana tabacum L. cv. NC89) was used in this study. After 9 weeks (before the flowering stage) of plant growth in a greenhouse, leaf samples were randomly collected. Using an axenic technique, $30 \mathrm{~g}$ of mixed leaves were placed into sterile flasks with acidified EtAc (ethyl acetate containing $0.2 \%$ glacial acetic acid). After sonication for $10 \mathrm{~min}$, the mixture was vortexed for $1 \mathrm{~h}$. After centrifugation, the extracted supernatant was dried under $\mathrm{N}_{2}$ gas and stored at $-20{ }^{\circ} \mathrm{C}$ until processing for subsequent analysis. All sample extractions were performed in triplicate. The control samples were treated with the same procedure, except that the leaves were sonicated and rinsed using sterile purified water before extraction with EtAc.

Extracts with AHL-like activity were detected by crossstreaking against AHL bioassay strains Agrobacterium tumefaciens A136 (McLean et al., 1997) and Chromobacterium violaceum CV026 (McClean et al., 1997). AHL profiling was confirmed using a Waters Micromass Q-Tof micromass spectrometer (LC/MS) system. All samples were applied to a C18 column (ZORBAX Eclipse XDB-C18, $5 \mu \mathrm{m} 250 \times 4.6 \mathrm{~mm}$; Agilent, USA) and eluted first using an isocratic profile of acetonitrile-water (60:40) for $15 \mathrm{~min}$ followed by a linear gradient from 60 to $100 \%$ acetonitrile in water over $5 \mathrm{~min}$. The effluent was ionized by electrospray ionization (ESI) and detected in the positive ion mode (Morin et al., 2003).

\subsection{Sample treatment and PLFA analysis}

The experimental design was a randomized complete block with three replications for each of the AHL treatments tested. 9-week-old tobacco plants were sprayed with $1 \mu \mathrm{M}$ or $10 \mu \mathrm{M}$ $\mathrm{N}$-(3-oxohexanoyl) homoserine lactone (3OC6HSL) and control treatments were sprayed with autoclaved distilled water. 30C6HSL was selected because it was the primary AHL extracted from the tobacco plant phyllosphere (Table 1).
Randomly collected leaves from the plants were sampled axenically every day for a week. Bacteria from leaves were collected for DNA extraction or PLFA analysis as described previously (Zhang et al., 2009).

The analysis of PLFA was performed as described previously with minor alterations (Bligh and Dyer, 1969). The composition of PLFA was determined using an Agilent 7890 GC (USA) on an HP-5 MS capillary column (J\&W Scientific, USA) coupled with 5897 MSD. The relative quantities of individual fatty acid methyl esters were quantified using $\mathrm{C}_{19: 0}$ as a standard and converted to cell numbers as described elsewhere (Mohanty et al., 2006). Phospholipid fatty acids were assigned to taxonomic groups as categorized elsewhere (Myrold et al., 2005). Briefly, terminally branched saturated PLFAs (i14:0, a15:0, i15:0, i16:0, a17:0, i17:0) were indicative of GP bacteria, whereas some monounsaturated PLFAs $(16: 1 \omega 7,17: 1,18: 1 \omega 7)$ were indicators of GN bacteria. Analysis of variance (one-way ANOVA) for independent samples was performed using SigmaPlot 11.0 (Systat Software Inc., USA). The level of significance was determined using the Duncan test at $P<0.05$ followed by original ANOVA results.

\subsection{Denaturing gradient gel electrophoresis analysis}

Total phyllosphere community DNA was extracted using a Fast DNA kit (Qbiogene, USA) according to the manufacturer's instructions. Purified total genomic DNA was used as the template for amplification of the V3 region of the small subunit rRNA gene using BA338fGC and UN518r primers (Lambais et al., 2006). PCR amplification was carried out as described previously (Zhang et al., 2009). DGGE analysis was performed with the Dcode Universal Mutation Detection system (BioRad, USA) according to the instruction manual. Purified PCR products were subjected to DGGE analysis using $8 \%$ polyacrylamide [acrylamide-bisacrylamide (37.5:1)] gels with a $40-55 \%$ denaturing gradient $(100 \%$ denaturant containing $7 \mathrm{M}$ urea and $40 \%$ formamide) and were electrophoresed at $60 \mathrm{~V}$ for $17 \mathrm{~h}$ at $60{ }^{\circ} \mathrm{C}$. After imaging, DNA band positions and intensities were detected using Quantity One software (BioRad, USA). The resulting DGGE profiles were analyzed, and cluster analyses were performed using the Minitab software program (Minitab Inc., USA).

Representative bands from the DGGE gels were excised and transferred to tubes with $50 \mu \mathrm{l}$ of sterile water for

Table 1

Acyl-homoserine lactones detected using LC-MS-MS in sample extracts from the tobacco phyllosphere.

\begin{tabular}{lllll}
\hline AHL & Parent ion & \multicolumn{2}{l}{ Fragmentation ions } & $\begin{array}{l}\text { Concentration } \\
\left(\mathrm{pmol} \mathrm{g}^{-1}\right)\end{array}$ \\
\cline { 2 - 4 } & $\begin{array}{l}\mathrm{M}+\mathrm{H}]^{+} \\
(\mathrm{m} / \mathrm{z})\end{array}$ & $\begin{array}{l}\text { Lactone } \\
\text { moiety }(\mathrm{m} / \mathrm{z})\end{array}$ & $\begin{array}{l}\text { Acyl-chain } \\
\text { moiety }(\mathrm{m} / \mathrm{z})\end{array}$ & \\
\hline $\mathrm{C} 6-$ & 200 & 102 & 99 & 5.2 \\
$3-\mathrm{O}-\mathrm{C} 6-$ & 214 & 102 & 113 & 9.8 \\
$\mathrm{C} 8-$ & 228 & 102 & 127 & 6.6 \\
$3-\mathrm{O}-\mathrm{C} 8-$ & 242 & 102 & 141 & 3.2 \\
C14- & 312 & 102 & 211 & 0.4 \\
\hline
\end{tabular}

$\mathrm{m} / \mathrm{z}=$ mass/charge ratio. 
overnight incubation at $4{ }^{\circ} \mathrm{C}$. PCR products were then reamplified using BA338f and UN518r primers and cloned into Escherichia coli using the pGEM-T vector (Promega, Madison, WI, USA). The approximately $200 \mathrm{bp}$ of rRNA gene sequences were analyzed to confirmed that no chimeric sequences were present (Ashelford et al., 2006) and were compared to the GenBank database sequences using BLASTN. Sequence data from this study have been deposited in GenBank under accession numbers HQ876198 to HQ876206.

\section{Results}

\subsection{Evidence of AHLs in the tobacco phyllosphere}

To understand the role of AHLs in the phyllosphere habitat, putative AHL compounds that were directly extracted from the phyllosphere were identified using bioassays and chemical analysis. Compounds from the tobacco phyllosphere extracts could induce color development in C. violaceum CV026 and A. tumefaciens A136. This indicates that AHLs are synthesized in the tobacco phyllosphere. Putative AHLs in the phyllosphere extracts were confirmed by comparing their retention times and mass spectra from LC-MS-MS with those of standard AHLs. Table 1 shows that several AHL autoinducers could be extracted from the phyllosphere. At least five different AHLs were detectable, including C6-, $\mathrm{O}-\mathrm{C} 6-, \mathrm{C} 8-, \mathrm{O}-\mathrm{C} 8-$, and C14-AHLs. Additionally, 3OC6HSL and $N$-octanoyl homoserine lactone (C8HSL) were the most abundant AHLs identified in the tobacco phyllosphere.

\subsection{Composition of the microbial community analyzed by PLFA}

PLFA profiles were generated to analyze the composition of the microbial community in the phyllosphere that responded to AHL treatment. Fig. 1 shows that the ratio of GN bacteria associated with plants treated with $1 \mu \mathrm{M}$ AHL decreased compared to control plants, in contrast to plants treated with $10 \mu \mathrm{M}$ AHL. The quantity of GP bacteria in the phyllosphere for plants treated with $1 \mu \mathrm{M}$ AHL was greater than in control plants and the ratio increased over time. Based on the mass of PLFA, the abundance of bacteria was estimated to be between 0.9 and $3.2 \times 10^{5}$ cells per gram of fresh leaves. The size of the bacterial population in the tobacco phyllosphere varied significantly between AHL treatments after $24 \mathrm{~h}(P<0.05)$.

\subsection{Structure of the bacterial community detected through analysis of $16 S$ rDNA}

The 16S rRNA fingerprints of DNA samples taken throughout the course of the AHL treatment were shown by DGGE assay (Fig. 2). The bacterial community's DGGE profiles were generally similar. Irrespective of treatment, bands e and i were dominant in all samples. However, some bands were unique to each AHL treatment, such as bands a, b,
A
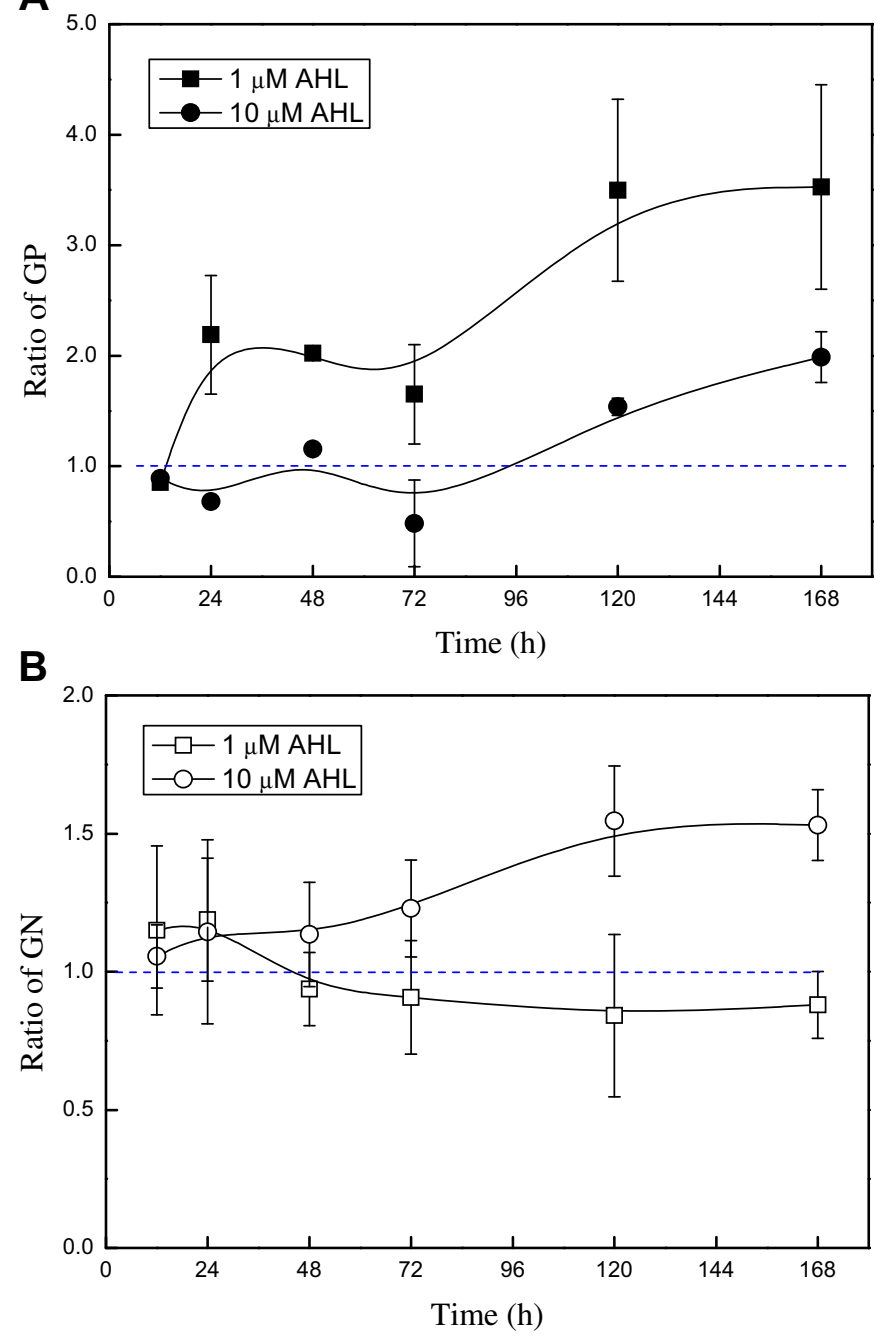

Fig. 1. Ratios of Gram-positive (A) and Gram-negative (B) bacterial phospholipid fatty acids (PLFAs) depending on different concentrations of acylhomoserine lactone (AHL) treatment over time. The ratio based on PLFA abundance was normalized by the control sample. GP, Gram-positive bacteria; GN, Gram-negative bacteria.

and $\mathrm{f}$. Compared to the control, the AHL-treated bacterial communities displayed more variability over time, particularly in the $1 \mu \mathrm{M}$ AHL-treated community.

Cluster analysis indicated that the bacterial communities could be grouped into two main clusters that share low levels of similarity (Fig. 2B). These clusters are designated C and S. The bacterial communities in the control treatment generally clustered together and were branched separately. The AHLtreated communities displayed similar clustering. This indicated that the control community was distinctly different from the AHL-treated bacterial communities. No other pattern variations were observed in bacterial communities treated with different concentrations of AHL. However, bacterial communities derived from samples taken at several time-points following $1 \mu \mathrm{M}$ AHL treatment could be further grouped into a cluster sharing $>70 \%$ similarity. The control was the only other treatment in which variation in the bacterial communities of the tobacco phyllosphere changed over time. 

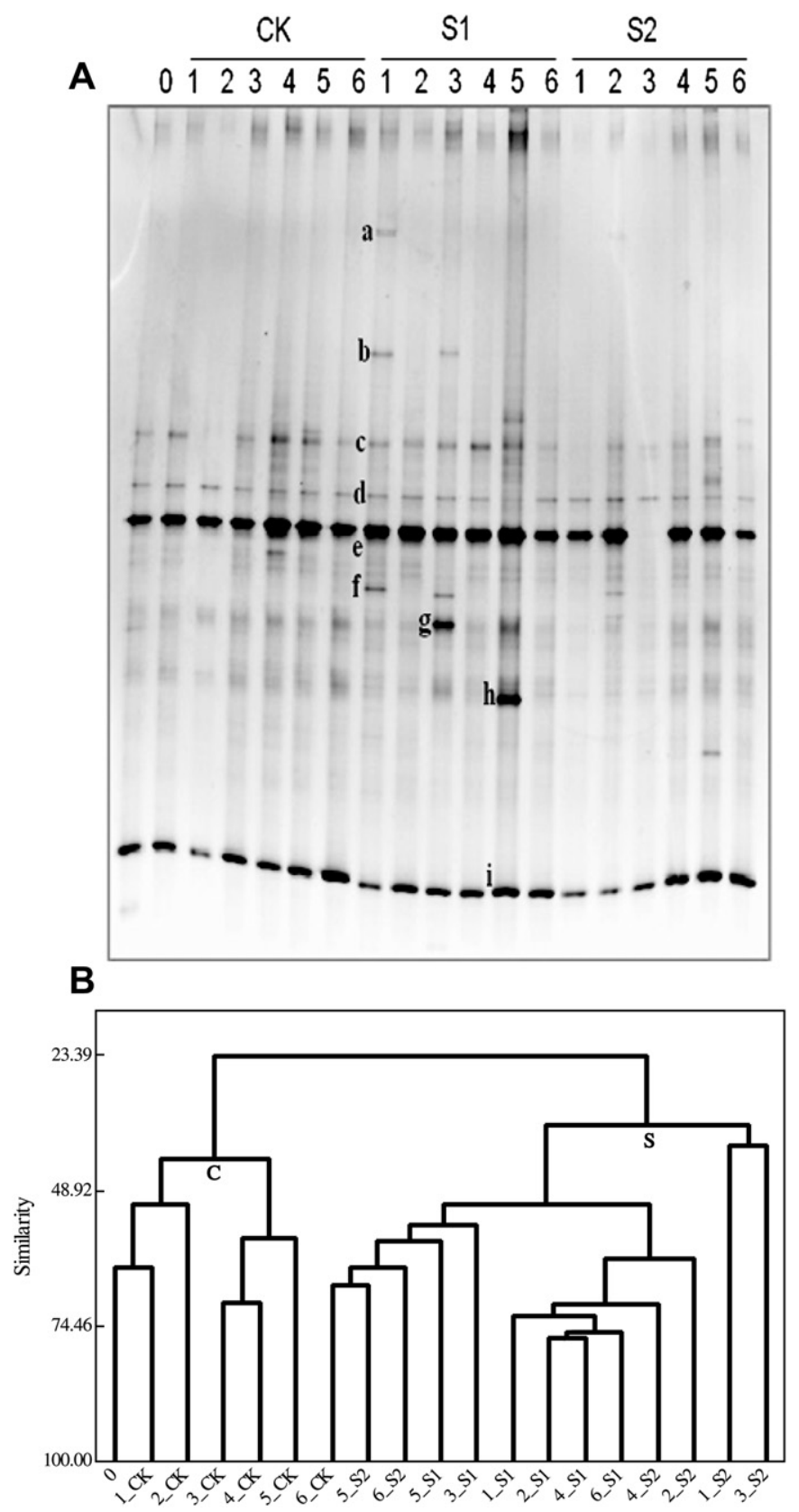

Fig. 2. (A) DGGE gel comparing community profiles obtained from the phyllosphere of tobacco leaves treated with controls (CK) or with different concentrations of AHLs over the course of $168 \mathrm{~h}[1 \mu \mathrm{M}$ (S1); $10 \mu \mathrm{M}$ (S2)]. The first lane (0) refers to plants prior to AHL treatment. Numbers $1-6$ represent samples taken at various time-points following treatment: $12 \mathrm{~h}, 24 \mathrm{~h}$, $48 \mathrm{~h}, 72 \mathrm{~h}, 96 \mathrm{~h}, 120 \mathrm{~h}, 144 \mathrm{~h}$ and $168 \mathrm{~h}$, respectively. Letters refer to bands that were excised and sequenced. (B) Dendrogram of clustering based on DGGE profiles, derived using UPGMA.

To further understand the influence of exogenous AHLs on bacterial community structure, phylogenetic information was obtained by sequencing. Nine bands (Fig. 2) were analyzed by sequence homology the results of which are presented in Table 2. Sequence data from the $16 \mathrm{~S}$ rDNA bands demonstrated that the predominant bacterial members were associated with the Proteobacteria phylum. Two bands were identified belonging to members of the Actinobacteria and Firmicutes phyla.

\section{Discussion}

A large portion of culturable plant-associated bacteria communicate with each other via QS systems (Cha et al., 1998). AHL-mediated interactions between culturable epiphytes on leaves have recently been highlighted in laboratory studies (Dulla and Lindow, 2009). With its complex microbial populations, the phyllosphere may be one of the largest microbial habitats on earth, and the ecological role of QS in this niche should be further studied (Redford et al., 2010). In this study, we mainly focused on assessing the presence of AHLs and AHL-mediated influences on the composition of the bacterial community in the tobacco phyllosphere.

Extracts from the tobacco phyllosphere showed putative AHL-like activity based on the results of a bioassay. Additionally, our data suggested that the dominant AHLs in the phyllosphere might consist of both short- and long-chain AHLs due to coloration of bioassay reporter strains CV026 and A136. Coloration is induced by short- and long-chain AHLs in these systems, respectively (McClean et al., 1997). The presence of several AHL molecules was supported by direct profiling of AHL molecules by LC-MS analysis (Table 1). Typically, different plant-associated bacteria respond to various AHL signaling compounds (Cha et al., 1998); therefore, it is not surprising that plant surfaces harbor a variety of AHLs. Previous studies have shown that at least $7 \%$ of culturable epiphytes are capable of AHL production in the phyllosphere (Dulla and Lindow, 2009). Considering that a large fraction of unculturable bacterial populations could synthesize AHLs (Lumjiaktase et al., 2010), it is possible that QS signaling molecules are able to modify the bacterial composition within this habitat. In previous studies, it has been suggested that leaf-associated $P$. syringae pv. syringae (Pss) B728a cells were prematurely autoinduced when $10 \mu \mathrm{M}$ AHL was sprayed on plants, leading to changes in behavior that were regulated by QS (Dulla and Lindow, 2009). Moreover,

Table 2

Identification of bacterial 16S rRNA sequences of DGGE bands obtained from the tobacco phyllosphere.

\begin{tabular}{llcl}
\hline Band $^{\mathrm{a}}$ & $\begin{array}{l}\text { Closest GenBank } \\
\text { match }\end{array}$ & Identity (\%) & Phylogenetic group \\
\hline $\mathrm{a}$ & $\begin{array}{l}\text { Pseudomonas sp. } \\
\text { Kocuria rhizophila }\end{array}$ & 100 & $\begin{array}{l}\text { Class Gammaproteobacteria } \\
\text { Class Actinobacteridae }\end{array}$ \\
$\mathrm{c}$ & $\begin{array}{l}\text { Uncultured } \\
\text { bacterium clone }\end{array}$ & 94 & $\begin{array}{l}\text { Unclassified bacteria } \\
\text { d }\end{array}$ \\
& $\begin{array}{l}\text { Uncultured } \\
\text { Pseudomonas sp. }\end{array}$ & 99 & Class Gammaproteobacteria \\
$\mathrm{e}$ & $\begin{array}{l}\text { Pseudomonas } \\
\text { aeruginosa }\end{array}$ & 100 & Class Gammaproteobacteria \\
$\mathrm{f}$ & $\begin{array}{l}\text { Pseudomonas sp. } \\
\text { Uncultured }\end{array}$ & 99 & $\begin{array}{l}\text { Class Gammaproteobacteria } \\
\text { Class Gammaproteobacteria }\end{array}$ \\
$\mathrm{h}$ & $\begin{array}{l}\text { Acinetobacter } \\
\text { Planococcus sp. }\end{array}$ & 109 & Firmicutes \\
$\mathrm{i}$ & $\begin{array}{l}\text { Uncultured } \\
\text { alphaproteobacterium } \\
\text { clone }\end{array}$ & 100 & Class Alphaproteobacteria \\
\end{tabular}

${ }^{\text {a }}$ The position of each band is shown in Fig. 2. 
a low-density culture of the engineered Pss can be induced when treated with 3OC6HSL of $1 \mu \mathrm{M}$ or greater (Dulla and Lindow, 2008). In the natural environment, the microenvironment of the leaf surface changes rapidly and is usually nonwater-saturated. These can inhibit AHL diffusion and make it at a high biologically active level (Dulla and Lindow, 2008). Considering this, we used concentrations of $1 \mu \mathrm{M}$ and $10 \mu \mathrm{M}$ AHLs to study the effect on the leaf-associated bacterial communities.

Fig. 1 indicates that different AHL treatments promoted changes in the composition of the bacterial community. Overall, GN bacteria populations appeared to increase when treated with $10 \mu \mathrm{M}$ AHL treatment over time relative to the control. This is likely because GN bacteria can survive in the limited nutrient conditions found on leaf surfaces, thereby using QS as a tool to compete with other epiphytes inhabiting this niche (Dulla et al., 2005; Lindow and Brandl, 2003). Indeed, AHL was mildly cytotoxic to some of the GP strains (Kaufmann et al., 2005), which may explain why the growth of GP bacterial populations treated with $10 \mu \mathrm{M}$ AHLs was weakly restricted before $120 \mathrm{~h}$. In contrast, the ratio of GP epiphytes increased when leaves were treated with $1 \mu \mathrm{M}$ AHL. This may be explained by the previous finding that GP bacteria use low concentrations of AHLs for energy and as a resource to grow (Yang et al., 2006). AHLs may not only play a role in intercellular signaling, but may also play non-signaling ecological roles (Manefield and Whiteley, 2007).

It is noteworthy that the AHL-treated bacterial communities clustered separately from the control group (Fig. 2B). This clustering is probably due to the effect of exogenous AHLs on the plant-associated bacterial community. Using a similar DGGE assay, McLean et al. demonstrated that a microbial community responded to the addition of exogenous AHLs (McLean et al., 2005). Meanwhile, the presence of AHLproducing bacteria strongly affected the behavior of $P$. syringae, providing evidence of AHL-mediated cross-talk between the phyllosphere bacteria (Dulla and Lindow, 2009). Therefore, it can be hypothesized that exogenous AHLs altered the composition of the phyllosphere bacterial community in our current study. As shown in the cluster dendrogram (Fig. 2B), while no obvious correlations were detected, variability in the structure of the bacterial community existed in the phyllosphere when treated with different concentration of AHLs. Typically, the threshold concentration of AHL needed to regulate the phenotype and function of leaf-associated bacteria by QS systems is not always constant, and the toxicity of these bacteria to their epiphytic neighbors could partially explain this complex phenomenon.

It is interesting that a few bands appeared specifically in response to the addition of $1 \mu \mathrm{M}$ AHL (Fig. 2A). Sequence analysis revealed that bands $b$ and $h$ were affiliated with the Actinobacteria and Firmicutes phyla, respectively (Table 2). Previous studies have shown that members of these phyla can degrade AHLs and utilize them as a carbon and/or nitrogen source (Morohoshi et al., 2009; Yang et al., 2006). This result corresponds with the increase in GP bacteria ratio analyzed by PLFA profile. There were no obvious changes in the DGGE banding patterns of the bacterial communities treated with $10 \mu \mathrm{M}$ AHL, implying that there was little diversity amongst the predominant bacterial members. The $16 \mathrm{~S}$ rDNA sequences of representative bacterial clones obtained from the tobacco phyllosphere revealed that members of the Proteobacteria phylum were numerically dominant in the bacterial communities (data not shown). This is generally consistent in a range of other studies (Delmotte et al., 2009). Additionally, the dominant bands corresponded to bacteria affiliated with the Gammaproteobacteria subphylum (Table 2). This subphylum includes the genera Pseudomonas and others that are capable of AHL production in the phyllosphere (Cha et al., 1998; Dulla and Lindow, 2009). Perhaps these dominant bacteria utilize QS-dependent mechanisms to ensure their survival over other epiphytic residents in the nutrientpoor phyllosphere.

In conclusion, we show that several AHL QS signals existed naturally in the tobacco phyllosphere and could play a role in the interaction between plant-associated bacteria. Moreover, the influence of the various concentrations of exogenous AHL on the composition of indigenous bacterial communities in the phyllosphere varied, potentially because AHLs have more complex ecological interactions in the natural habitat. This research does not clarify the effect of different AHLs on microbial communities and this will be addressed in our future research. However, our present findings do provide insight into how plant interactions with phytopathogens can be modified through manipulation of AHLs in the phyllosphere. The effect of this manipulation will be based on the QS signal molecules of different plants.

\section{Acknowledgments}

The authors wish to express their gratitude to Professor R. McLean (Department of Biology, Texas State University) for kindly providing AHL reporter strains. We also thank G. Zhao at Ohio State University for his assistance with English language editing of the manuscript. This work was financially supported by a grant from the National Natural Science Foundation of China (grant no. 21177145).

\section{References}

Ashelford, K.E., Chuzhanova, N.A., Fry, J.C., Jones, A.J., Weightman, A.J., 2006. New screening software shows that most recent large $16 \mathrm{~S}$ rRNA gene clone libraries contain chimeras. Appl. Environ. Microbiol. 72, 5734-5741.

Bligh, E.G., Dyer, W.J., 1969. A rapid method for total lipid extraction and purification. Can. J. Biochem. Physiol. 37, 911-917.

Cha, C., Gao, P., Chen, Y.C., Shaw, P.D., Farrand, S.K., 1998. Production of acyl-homoserine lactone quorum-sensing signals by gram-negative plantassociated bacteria. Mol. Plant Microbe Interact. 11, 1119-1129.

Delmotte, N., Knief, C., Chaffron, S., Innerebner, G., Roschitzki, B., Schlapbach, R., von Mering, C., Vorholt, J.A., 2009. Community proteogenomics reveals insights into the physiology of phyllosphere bacteria. Proc. Natl. Acad. Sci. U. S. A. 106, 16428-16433.

Dulla, G., Lindow, S.E., 2008. Quorum size of Pseudomonas syringae is small and dictated by water availability on the leaf surface. Proc. Natl. Acad. Sci. U. S. A. 105, 3082-3087. 
Dulla, G., Marco, M., Quinones, B., Lindow, S., 2005. A closer look at Pseudomonas syringae as a leaf colonist - the pathogen $P$. syringae thrives on healthy plants by employing quorum sensing, virulence factors, and other traits. ASM News 71, 469-475.

Dulla, G., Lindow, S.E., 2009. Acyl-homoserine lactone-mediated cross talk among epiphytic bacteria modulates behavior of Pseudomonas syringae on leaves. ISME J. 3, 825-834.

Fray, R.G., Throup, J.P., Daykin, M., Wallace, A., Williams, P., Stewart, G., Grierson, D., 1999. Plants genetically modified to produce $N$-acylhomoserine lactones communicate with bacteria. Nat. Biotechnol. 17, 1017-1020.

Kaufmann, G.F., Sartorio, R., Lee, S.H., Rogers, C.J., Meijler, M.M., Moss, J.A., Clapham, B., Brogan, A.P., Dickerson, T.J., Janda, K.D., 2005. Revisiting quorum sensing: discovery of additional chemical and biological functions for 3-oxo- $N$-acylhomoserine lactones. Proc. Natl. Acad. Sci. U. S. A. 102, 309-314.

Lambais, M.R., Crowley, D.E., Cury, J.C., Bull, R.C., Rodrigues, R.R., 2006. Bacterial diversity in tree canopies of the Atlantic forest. Science 312, 1917.

Lindow, S.E., Brandl, M.T., 2003. Microbiology of the phyllosphere. Appl. Environ. Microbiol. 69, 1875-1883.

Loh, J., Pierson, E.A., Pierson 3rd, L.S., Stacey, G., Chatterjee, A., 2002. Quorum sensing in plant-associated bacteria. Curr. Opin. Plant Biol. 5, 285-290.

Lumjiaktase, P., Aguilar, C., Battin, T., Riedel, K., Eberl, L., 2010. Construction of self-transmissible green fluorescent protein-based biosensor plasmids and their use for identification of $\mathrm{N}$-acyl homoserineproducing bacteria in lake sediments. Appl. Environ. Microbiol. 76, 6119-6127.

Manefield, M., Whiteley, A.S., 2007. Acylated homoserine lactones in the environment: chameleons of bioactivity. Philos. Trans. R Soc. Lond. B Biol. Sci. 362, 1235-1240.

McClean, K.H., Winson, M.K., Fish, L., Taylor, A., Chhabra, S.R., Camara, M., Daykin, M., Lamb, J.H., Swift, S., Bycroft, B.W., Stewart, G., Williams, P., 1997. Quorum sensing and Chromobacterium violaceum: exploitation of violacein production and inhibition for the detection of $\mathrm{N}$ acylhomoserine lactones. Microbiology 143, 3703-3711.
McLean, R.J.C., Barnes, M.B., Windham, M.K., Merchant, M., Forstner, M.R.J., Fuqua, C., 2005. Cell-cell influences on bacterial community development in aquatic biofilms. Appl. Environ. Microbiol. 71, 8987-8990.

McLean, R.J.C., Whiteley, M., Stickler, D.J., Fuqua, W.C., 1997. Evidence of autoinducer activity in naturally occurring biofilms. FEMS Microbiol. Lett. 154, 259-263.

Mohanty, S.R., Bodelier, P.L., Floris, V., Conrad, R., 2006. Differential effects of nitrogenous fertilizers on methane-consuming microbes in rice field and forest soils. Appl. Environ. Microbiol. 72, 1346-1354.

Morin, D., Grasland, B., Vallee-Rehel, K., Dufau, C., Haras, D., 2003. On-line high-performance liquid chromatography-mass spectrometric detection and quantification of $\mathrm{N}$-acylhomoserine lactones, quorum sensing signal molecules, in the presence of biological matrices. J. Chromatogr. 1002 79-92.

Morohoshi, T., Someya, N., Ikeda, T., 2009. Novel $N$-acylhomoserine lactonedegrading bacteria isolated from the leaf surface of Solanum tuberosum and their quorum-quenching properties. Biosci. Biotechnol. Biochem. 73, 2124-2127.

Myrold, D.D., McMahon, S.K., Williams, M.A., Bottomley, P.J., 2005 Dynamics of microbial communities during decomposition of carbon-13 labeled ryegrass fractions in soil. Soil Sci. Soc. Am. J. 69, 1238-1247.

Ng, W.L., Bassler, B.L., 2009. Bacterial quorum-sensing network architectures. Annu. Rev. Genet. 43, 197-222.

Pacheco, A.R., Sperandio, V., 2009. Inter-kingdom signaling: chemical language between bacteria and host. Curr. Opin. Microbiol. 12, 192-198.

Redford, A.J., Bowers, R.M., Knight, R., Linhart, Y., Fierer, N., 2010. The ecology of the phyllosphere: geographic and phylogenetic variability in the distribution of bacteria on tree leaves. Environ. Microbiol. 12, 2885-2893.

Waters, C.M., Bassler, B.L., 2005. Quorum sensing: cell-to-cell communication in bacteria. Annu. Rev. Cell Dev. Biol. 21, 319-346.

Yang, W.W., Han, J.I., Leadbetter, J.R., 2006. Utilization of homoserine lactone as a sole source of carbon and energy by soil Arthrobacter and Burkholderia species. Arch. Microbiol. 185, 47-54.

Zhang, B.G., Bai, Z.H., Hoefel, D., Tang, L., Wang, X.Y., Li, B.J., Li, Z.M., Zhuang, G.Q., 2009. The impacts of cypermethrin pesticide application on the non-target microbial community of the pepper plant phyllosphere. Sci. Total Environ. 407, 1915-1922. 